\title{
Um Balanço das Políticas Públicas de Trabalho, Emprego e Renda Para a População LGBT no Brasil e na Argentina (2004-2014)
}

\section{Bruna Andrade Irineu}

Professora do Departamento de Serviço Social e do Programa de Pós-Graduação em Política Social da Universidade Federal de Mato Grosso - PPGPS/UFMT. Coordenadora do Núcleo de Estudos e Pesquisas sobre a Organização da Mulher e Relações de Gênero - Nuepom/UFMT. http://lattes.cnpq.br/8676883646497204. https://orcid.org/0000-0003-1158-5000. brunairineu@gmail.com

\section{Brendhon Andrade Oliveira}

Mestrando em Direito pela Universidade Federal de Mato Grosso (PPGD/UFMT). Graduação em Direito pela Universidade Federal do Tocantins (UFT). Membro do Núcleo de Estudos e Pesquisa Sobre a Organização da Mulher e Relações de Gênero (Nuepom/UFMT) e do Grupo de Pesquisas em meio ambiente do trabalho equilibrado como componente do trabalho decente (GPMAT/UFMT). http://lattes.cnpq.br/1460155426305927. https://orcid.org/0000-0001-8204-651X. andradebrendhon@gmail.com

Este trabalho é fruto da pesquisa intitulada "Direitos LGBT e Políticas Públicas de Trabalho, Emprego e Renda no Brasil e na Argentina (2004-2014): Mapeamento Crítico Preliminar", vinculada ao Núcleo de Estudos, Pesquisas e Extensão em Sexualidade, Corporalidades e Direitos da Universidade Federal do Tocantins - UFT. O estudo mapeou documentos que nortearam as políticas públicas de trabalho no Brasil e Argentina. Em um contexto de refração dos direitos humanos após avanço neoliberal por intermédio dos governos do campo de esquerda e, consequentemente, do retorno de governos de direita tanto na Argentina quanto no Brasil, torna-se central refletir sobre o período de gestão governamental do Partido Justicialista (Argentina) e Partido dos Trabalhadores (PT). Durante os anos de governo destes partidos, pode-se observar a criação de uma agenda anti-homofobia nestes dois países, por meio de ações concernentes aos direitos LGBT (lésbicas, gays, bissexuais, travestis e transexuais) via Poder Executivo e Judiciário, no caso brasileiro, ou via Poder Legislativo, como na situação argentina. O processo de organização das lutas da população LGBT remonta de tempos em que ambos os países vivenciavam a ditadura militar entre o final da década de 60 e 70. Com a redemocratização, esses países vão vivenciar experiências distintas de tensionamento da sociedade civil junto ao Estado. A demanda por trabalho, emprego e renda subjaz a segmentos diversos cuja posição de classe social referencia-se de maneira latente; entretanto a identidade de gênero e a orientação sexual passam a ser apresentadas como marcadores sociais que também vão produzir desigualdade social no acesso à qualificação e ao trabalho formal. Palavras-chave: Direitos. Políticas públicas. LGBT. Trabalho. Emprego.

\section{A BALANCE OF PUBLIC POLICIES ON WORK, EMPLOYMENT AND INCOME FOR LGBT POPULATION IN BRAZIL AND ARGENTINA (2004-2014)}

\section{ABSTRACT}

This paper is the result of the research entitled "LGBT Rights and Public Policies of Employment and Income in Brazil and Argentina (2004-2014): Preliminary Critical Mapping" linked to the Center for Studies, Research and Extension in Sexuality, Corporalities and Rights of the Federal University of Tocantins - UFT. The study mapped documents that guide the public policies of work in Brazil and Argentina. In a context of refraction of human rights following the recent return of conservative governments in both Argentina and Brazil, it becomes central to reflect on the period of governmental management of the Partido Justicialista (Argentina) and Partido dos Trabalhadores (PT). During the years of government of these parties, one can observe the consolidation of the anti-homophobia agenda in these two countries, through actions concerning LGBT rights (lesbians, gays, bisexuals, transvestites and transsexuals) via the Executive and Judiciary branches, in the Brazilian case or via the Legislative Branch, as in the Argentine situation. The process of organizing the struggles of the LGBT population goes back to a time when both countries experienced the military dictatorship between the late 1960s and 1970s. With redemocratization these countries will experience different experiences of tensioning civil society with the state. The demand for work, employment and income underlies diverse segments whose position of social class is latently referenced, however, gender identity and sexual orientation are brought to be social markers that will also produce social inequality in access to qualification and formal work.

Keywords: Rights. Public policies. LGBT. Work.

1 Introdução. 2 Pensar corpo, gênero e sexualidade. 3 Levantamento das políticas públicas de trabalho, emprego e renda no Brasil. 4 Identificando as políticas públicas de trabalho, emprego e renda na Argentina. 5 Considerações finais. 6 Referências. 


\section{Humanos e \\ Democracia}

\section{INTRODUÇÃO}

Este artigo é resultante da pesquisa "Mapeamento crítico das políticas públicas de educação, saúde e trabalho para a população LGBT (Lésbicas, Gays, Bissexuais, Travestis e Transexuais) na América Latina: um estudo comparativo entre Brasil e Argentina", vinculada ao Núcleo de Estudos, Pesquisa e Extensão e Sexualidade, Corporalidades e Direitos, da Universidade Federal do Tocantins - UFT -, cujo recorte temporal data de 2004 a 2014.

Com a emergência de governos populares nos anos pós-2000 no Brasil e na Argentina, após longos períodos de ditadura militar e em um momento de forte consolidação de estratégias neoliberais, distintas conjunturas políticas, econômicas e sociais emergiram com o processo de redemocratização. Tendo em mente que as pautas relacionadas aos direitos humanos em âmbito global caminharam também com essas mudanças, coube a este estudo verificar no campo dos direitos da população LGBT as iniciativas e ações governamentais voltadas a esta população, observando seu impacto no âmbito do enfrentamento às violações dos direitos humanos deste segmento.

As demandas por trabalho, emprego e renda reverberam o campo dos direitos sociais, que, por sua vez, no contexto brasileiro, encontram-se previstos na Constituição Federal de 1988 a partir de luta histórica da classe trabalhadora. Em âmbito global, este debate também se explicita na Declaração Universal de Direitos Humanos, especificamente com o Pacto Internacional dos Direitos Econômicos, Sociais e Culturais, que entrou em vigor em 1976 em âmbito internacional, e no Brasil em 1992, com o envio da Carta de Adesão. É importante discutir, todavia, que ações governamentais de cunho caritativo e assistencialista por meio de programas estatais não devem ser compreendidas como forma ideal e séria de responder as demandas concretas por redistribuição de renda. Lidar seriamente com os direitos sociais e econômicos envolve criticar a concepção de "necessidades mínimas" para ampliar a ideia de "necessidades básicas" (PEREIRA, 2006).

Diante disso, é inegável que a identidade de gênero e a orientação sexual compõem as dimensões da vida social dos sujeitos, o que as torna marcadores sociais da diferença que, no contexto de violência e violações de direitos, são elevadas a desigualdades sociais. Sobre essas dimensões, é nítido que "uma delas é a inserção na divisão sociotécnica do trabalho, a atividade laborativa e a possibilidade de geração de renda" (ALMEIDA; PILAR; GEBRATH, 2014, p. 191). Do mesmo modo, compreendendo a interseccionalidade desses marcadores sociais na constituição das identidades dos sujeitos, e entende-se como necessário perceber o lugar dos direitos LBGTs nas políticas públicas de trabalho, emprego e renda, bem como o lugar dessas políticas na agenda do ativismo de lésbicas, gays, bissexuais, travestis, transexuais e transgêneros.

Feito tais considerações, a proposta da pesquisa é mapear os documentos que tratam de direitos e políticas públicas de trabalho no Brasil e Argentina no período de 2004 a 2014. Em seguida, elaborou-se uma análise crítica sobre as diretrizes que trazem esses direitos e políticas. Assim, realizou-se levantamento e pesquisas bibliográficas a partir de Estudos Queer, Gays, Lésbicos e Feministas. A investigação utilizou-se da análise documental como técnica de coleta de dados, tendo em vista "a importância dessa estratégia como alternativa de investi- 
gação dadas as contribuições que uma análise crítica e aprofundada de determinados documentos pode aportar" (PRATES; PRATES, 2009, p. 120). Diante deste levantamento, expomos os documentos que compõem o corpus deste estudo.

Tabela 1 - Fonte Documental da Pesquisa

\begin{tabular}{|c|c|c|}
\hline País & Documentos & Ano \\
\hline \multirow{3}{*}{ Brasil } & Programa Brasil sem Homofobia & 2004 \\
\cline { 2 - 3 } & $\begin{array}{c}\text { Texto Base e Anais da 2a Conferência Nacional de Direitos } \\
\text { Humanos LGBT }\end{array}$ & 2011 \\
\hline \multirow{2}{*}{ Argentina } & \begin{tabular}{c} 
De la ley a la práctica: conceptos desde un paradigma igualitário \\
\cline { 2 - 3 }
\end{tabular} & 2012 \\
\hline
\end{tabular}

Fonte: Pesquisa direta.

Empregamos a análise de conteúdo para a verificação dos dados coletados, que, conforme Bauer e Gaskell (2002), "é uma técnica para produzir inferências de um texto focal para seu contexto social de maneira objetivada" (p. 191). A partir desses documentos oficiais, analisou-se a formulação das ações para efetivação dos direitos LGBTs e políticas públicas de Trabalho, Emprego e Renda no Brasil e na Argentina.

\section{PENSAR CORPO, GÊNERO E SEXUALIDADE}

Acreditamos que o recorte das políticas de trabalho, emprego e renda dentro do contexto das políticas públicas lésbicas, gays, bissexuais, travestis e transexuais (LGBT), contribuem para que compreendamos a articulação dos direitos sociais no contexto dos direitos humanos nestes dois países. Para tanto, antes de aprofundarmos nesse recorte é importante salientar conceitos e categorias teóricas que consubstanciam o desenvolvimento deste estudo.

As categorias analíticas "corpo", "gênero", "sexualidade", "direitos", "políticas públicas" e "trabalho", assim como as categorias êmicas "emprego" e "renda", foram utilizadas articulando-as às subcategorias "direitos LGBT" e "políticas públicas LGBT". Corroboramos concepções teórico-políticas que criticam a sociabilidade perversa do capital, a ideia de Estado mínimo no campo das políticas sociais e o essencialismo das identidades, filiando-nos às correntes construtivistas no debate de gênero e sexualidade, bem como ao debate gramsciniano sobre Estado e sociedade civil.

Nesse sentido, entendemos que "o corpo é socialmente construído" (LE BRETON, 2007, p. 27), portanto "a determinação de lugares ou das posições sociais dos sujeitos no interior de um grupo é referida aos seus corpos" (LOURO, 2004, p. 36). O gênero e a sexualidade são marcadores sociais do corpo que colocam as pessoas em seus lugares a partir da hierarquização da vida social, e tornam essas marcas dispositivos de poder. Assim, Louro (2004) alerta que qualquer transgressão às fronteiras de gênero ou de sexualidade aloca os sujeitos que escapam à norma no campo do desvio e da diferença. Nessa perspectiva, compreendemos que o gênero e a sexualidade estão circunscritos em uma inteligibilidade, denominada de sistema sexo-gênero-desejo.

Certa premissa, bastante consagrada, costuma afirmar que determinado sexo (entendido, neste caso, em termos de características biológicas) indica determinado gênero e este gênero, por sua vez, indica o desejo ou induz a ele. Essa sequência supõe e institui uma 


\section{Humanos e \\ Democracia}

coerência e uma continuidade entre sexo-gênero-sexualidade. Ela supõe e institui uma consequência, ela afirma e repete uma norma, apostando numa lógica binária pela qual o corpo, identificado como macho ou como fêmea, determina o gênero (um de dois gêneros possíveis: masculino ou feminino) e leva a uma forma de desejo (especificamente, o desejo dirigido ao sexo/gênero oposto) (LOURO, 2004, p. 38).

Diante da realidade de desrespeito dos direitos humanos da população LGBT, é importante mencionar Foucault (1999) sobre o disciplinamento dos corpos:

Métodos que permitem o controle minucioso das operações do corpo, que realizam a sujeição constante de suas forças e lhes impõem uma relação de docilidade-utilidade, são o que podemos chamar as "disciplinas" (p. 118).

Dessa forma, compreendemos que os corpos são disciplinados por meio de uma "coerção sem folga" (FOUCAULT, 1999, p. 118), e que "é dócil um corpo que pode ser submetido, que pode ser utilizado, que pode ser transformado e aperfeiçoado" (p. 118).

Há uma pirâmide social que classifica os corpos que importam e os que não importam. Para a construção dessa pirâmide, os marcadores do corpo são utilizados para remeter os corpos aos seus lugares, utilizando-se de uma hierarquia que dispõe os corpos em posições boas e ruins, pecado e puro, útil e não útil, por exemplo. Nessa pirâmide, temos a hierarquização da sexualidade que apresenta, compulsoriamente, a heterossexualidade como uma única forma de vivência da sexualidade de maneira saudável, o que entenderemos por heteronormatividade (BUTLER, 2003).

A ordem de gênero explicita-se nas hierarquias que subjazem as masculinidades e as feminilidades, convertidas em processos de subordinação e dominação geradores do sexismo, que, por sua vez, supervalorizam o masculino em detrimento do feminino. Aqui também percebemos a hierarquização de outros marcadores sociais, tais como raça, etnia, geração, regionalidades e classe social. Assim sendo, as hierarquias explícitas nas marcas de poder que se expressam no corpo demonstram imbricamentos nas relações de poder e também nos processos de resistência às lógicas hierárquicas.

Sobre esses processos de resistência, como visto em Louro (2004), há corpos desviantes. Cabe questionar: Quais os efeitos ao disciplinamento dos corpos à insubordinação? De acordo com Foucault (1999), "a disciplina "fabrica" indivíduos, ela é a técnica específica de um poder que toma os indivíduos ao mesmo tempo como objetos e como instrumentos de seu exercício" (FOUCAULT, 1999, p. 143).

Essas construções sociais hierarquizantes, perpassadas pelo poder disciplinar, são percebidas no imaginário social, atuam de forma integrada e inter-relacionada, transitam entre as identidades e atravessam determinantes de diversas naturezas (o senso comum, o trabaIho, o direito, a cultura, etc.). Nesse sentido, é interessante mencionar os dados refletidos por Almeida, Pilar e Gebrath (2014) em um estudo sobre as relações de trabalho como um aspecto da assistência à saúde de pessoas trans:

As trajetórias de vida de mulheres e homens transexuais constituem a síntese absolutamente singular de suas inserções de classe social, de gênero e "raciais", bem como de suas características culturais, etárias, de suas carreiras sexuais, entre outras. Como sugere Safiotti (1992, p. 191), somente as "análises concretas de fatos reais poderão mostrar 
como as vivências humanas apresentam um colorido de classe e um colorido de gênero" e que estas dimensões são, portanto, inseparáveis. Em direção semelhante, o sociólogo Adalberto Cardoso (2013, p. 132) demonstrou, a partir de dados sobre o mercado de trabalho brasileiro, que, nele, "ser homem traz vantagens duráveis e positivas, em relação a ser mulher" e "a cor não branca traz desvantagens relativas duráveis, embora bem menos intensas do que os indicadores anteriores (p. 190-191).

Por consequência, as relações de trabalho da população LGBT - e de qualquer outro/a sujeito - produzem efeitos diretos sobre a vida social, seja em campo da saúde (física e psicológica), seja no contexto social em que vive. Por isso, apontamos aqui para a necessidade de compreender as questões que envolvem as identidades de modo interseccional, as lutas sociais e os projetos societários, para, assim, perceber, de forma minuciosa, os processos de opressão e exploração social em toda sua dinâmica. A discriminação e repressão no ambiente de trabalho, principalmente para aqueles/as que manifestam uma discordância no estereótipo - de gênero, raça ou sexualidade - mais visível, geram um mal-estar para essas pessoas.

[...] podemos imaginar que os indivíduos menos "à vontade", os mais fisicamente "encurralados", "bloqueados", "reprimidos" tanto na expressão real como simbólica do corpo, são aqueles que as relações de trabalho expõem à agressividade mais direta, enquanto a profissão lhes proíbe manifestar, em troca, a menor agressividade... Essas categorias interiorizariam seu mal-estar social e mal-estar físico (LE BRETON, 2007, p. 87).

Além disso, "o fato da divisão sociotécnica do trabalho ser, antes de tudo, sexual, aqueles que põe o gênero que lhes foi imposto ao nascerem em discussão têm maior dificuldade nas atividades profissionais que, em geral, são bastante generificadas" (ALMEIDA; PILAR; GEBRATH, 2014, p. 192). Acontece que "a fronteira entre a homossexualidade, a travestilidade e a transexualidade é bastante borrada", e, portanto, compreendemos que as pessoas LGBTs, para o entendimento social, transgridem tanto às barreiras do gênero quanto às da sexualidade.

Outro fator gerado pelo efeito da LGBTfobia no campo do Trabalho e Emprego que não poderíamos deixar de apontar, é a informalidade. Em razão dessas transgressões e discordâncias das normas do gênero e da sexualidade, muitas vezes as pessoas LGBTs são jogadas para o campo da informalidade, e, entre seus efeitos, temos a "desproteção nos termos da seguridade social brasileira (perda de direitos previdenciários e trabalhistas)" (ALMEIDA; PILAR; GEBRATH, 2014, p. 193). Obviamente que, de maneira geral, em um modo de produção fundamentalmente marcado por um conjunto de desigualdades como o sistema capitalista, a tendência à ampliação do campo da informalidade e da desproteção social atinge toda classe trabalhadora. Cabe articular, todavia, essa consideração ao contexto das transformações no mundo do trabalho, mas também as maneiras de sofisticação desse sistema nos processos de opressão e exploração a segmentos sociosexuais minoritários.

Tendo em vista esse cenário de violências e desproteções da população LGBT, compreendemos a responsabilidade do Estado em promover, por intermédio de direitos e políticas sociais, aqui especificamente de Trabalho, Emprego e Renda, acesso a ingresso ao mercado de trabalho, garantia de emprego formal e redistribuição de renda, sem discriminação por identidade de gênero e/ou orientação sexual. 


\section{Humanos e \\ Democracia}

Nesse sentido, a respeito das políticas públicas, Souza (2003) acredita que a formulação de políticas públicas deve ser compreendida como o processo por meio do qual os governos "traduzem seus propósitos em programas e ações, que produzirão resultados ou as mudanças desejadas no mundo real" (p. 13). É possível apontar também, entretanto, que esses programas e ações possuem níveis distintos de compromisso com a ideia de proteção social a depender das vinculações partidárias e filiações a determinadas concepções de Estado. Ou seja, uma política governamental terá, na sua formulação, características aliadas ao projeto societário ao qual aquele governo se vincula.

Entendendo, então, políticas públicas como uma resposta do Estado ante as demandas da sociedade civil, Mello, Avelar e Maroja (2012) nos fornecem indicadores das dificuldades de implementação de políticas públicas referentes à sexualidade:

Em particular, no que diz respeito às políticas públicas no campo da sexualidade, convém ainda destacar que elas são permeadas de peculiaridades, já que o ponto de partida para sua formulação e implementação é basicamente a necessidade de mudança de crenças, valores e tradições há muito prevalecentes no imaginário coletivo (p. 294).

Assim, as políticas públicas no campo da sexualidade, e também do gênero, geram um tensionamento com crenças, valores e tradições, o que nos remete, de imediato, às religiões no Brasil e na Argentina, sobretudo as de matriz judaico-cristã, tendo em vista que são majoritárias em termos populacionais nos referidos países. Nesse sentido, os grupos religiosos que confessam o cristianismo têm desenvolvido papel importante para "frear" a criação de políticas públicas e aprovação de legislações que versem sobre a diversidade sexual e de gênero.

Os discursos dessas instituições colocam as práticas homoeróticas como transgressões à lei da natureza ou de Deus, que teria criado dois seres de sexos diferentes para se complementarem e procriarem. Nesse sentido, a homossexualidade e os indivíduos que a praticam são percebidos como ameaças às ordens social, política, moral e, em alguns casos, legal das sociedades" (MACHADO; PICCOLLO, 2010, p. 117).

Valendo-se da homossexualidade como ameaça, essas instituições religiosas tomam o "pânico moral como parte de estratégias", buscando veicular essa ideologia por meio de "mensagens e imagens que incitam ao medo", como uma "arma política que opera por meio de uma mobilização do senso comum" (NATIVIDADE; OLIVEIRA, 2013, p. 117).

\section{LEVANTAMENTO DAS POLÍTICAS PÚBLICAS DE TRABALHO, EMPREGO E RENDA NO BRASIL}

Nesse momento cuidaremos primeiramente de analisar o processo de construção dos direitos e políticas públicas, bem como analisar o conteúdo dos documentos Programa Brasil sem Homofobia (BRASIL, 2004) e do Texto-Base e Anais da 2a Conferência Nacional LGBT (BRASIL, 2011).

O Programa Brasil Sem Homofobia (BSH) foi proposto no ano de 2004 pela Secretaria Especial de Direitos Humanos, e tinha como escopo a promoção da "cidadania GLBT a partir da equiparação de direitos e do combate à violência e à discriminação homofóbicas, respeitando a especificidade de cada um desses grupos populacionais" (BRASIL, 2004, p. 11). Este 
foi o primeiro documento governamental de políticas públicas voltadas especificamente à população LGBT no Brasil. Anteriormente, no governo Fernando Henrique Cardoso, houve a inserção de algumas ações dentro do Programa Nacional de Direitos Humanos I e II.

Para podermos cumprir a proposta de análise desses documentos, faz-se necessário resgatar os dados da pesquisa produzida pelo grupo Ser-Tão, da Universidade Federal de Goiás, que mapeou as políticas públicas para a população LGBT, na qual encontramos um estudo específico sobre as Políticas Públicas de Trabalho, Assistência Social e Previdência Social para a População LGBT. De acordo com este estudo:

O programa se desdobra em cinquenta e três (53) ações, divididas em onze (11) eixos, voltadas para "apoio a projetos de fortalecimento" de instituições que promovam a cidadania e o combate à homofobia; capacitação de representantes do movimento LGBT; disseminação de informações "sobre direitos, de promoção da auto-estima homossexual"; e incentivo à denúncia de violação de direitos LGBT (IRINEU et al., 2010, p. 176).

A pesquisa apontou, ainda, que o programa BSH refere-se apenas a discriminações no ambiente de trabalho, prevendo quatro diretrizes para o combate à LGBTfobia por meio de qualificação profissional dos segmentos discriminados por orientação sexual e identidade de gênero. Vale ressaltar que um dos objetivos do BSH foi a realização da I Conferência Nacional de Políticas Públicas para Lésbicas, Gays, Bissexuais, Travestis e Transexuais que ocorreu em 2008. Nesta conferência foram aprovadas 559 deliberações, quando 37 eram referentes ao Trabalho e Emprego, que, por sua vez, era um dos dez eixos temáticos. Após a primeira conferência, em 2009, o governo federal lançou o Plano Nacional de Promoção da Cidadania e Direitos Humanos LGBT, que continha 51 diretrizes e 180 ações, posto que, destas, somente 10 eram de responsabilidade do Ministério do Trabalho e Emprego (MTE). Deste modo, é notória a incipiência de ações de trabalho, emprego e renda nestes primeiros documentos da política nacional LGBT, demonstrando uma proeminência de ações em áreas em que o diálogo da sociedade civil continha uma certa consolidação, como a Saúde, a Educação e a Segurança Pública, e reforçando um lugar da agenda anti-homofobia em âmbito do Executivo, ainda vinculado ao debate do combate ao HIV/aids e à violência e pouco articulado ao campo da seguridade social enquanto política de proteção social.

Como objetivo do I Plano Nacional LGBT, o Conselho Nacional de Combate à Discriminação e Promoção dos Direitos de Lésbicas, Gays, Bissexuais, Travestis e Transexuais (CNCD/ LGBT), vinculado à Secretaria de Direitos Humanos (SDH/PR), foi criado por meio do Decreto no 7.388, de 9 de dezembro de 2010. Esse Conselho é um órgão que une sociedade civil e Estado e, basicamente, tem a função de verificar a efetivação das políticas públicas, atuando como um espaço de articulação e de controle social. Em 2011 o CNCD-LGBT coordenou a organização da II Conferência Nacional de Políticas Públicas e Direitos Humanos LGBT. A SDH/ PR produziu um documento que orientava a conferência de 2011, nomeado de Texto-Base. $O$ mesmo prestava contas das ações do I Plano LGBT, e, juntamente com este material, reunindo as propostas aprovadas na II Conferência, o CNCD-LGBT disponibilizou, posteriormente, os Anais da II Conferência Nacional LGBT.

Analisando estes documentos, observa-se nos Anais que as propostas da Conferência foram divididas em 15 eixos, e cada uma possuía, em média, 5 diretrizes. Um desses eixos é intitulado "Trabalho, Geração de Renda e Previdência" (BRASIL, 2011, p. 124), com 5 diretri- 


\section{Humanos e}

Democracia

zes, em que 2 são referentes à área da Previdência Social. Das 5 diretrizes presentes nos Anais mencionados, as demandas que envolvem trabalho, emprego e renda apontavam para a i) criação de um sistema de inserção no trabalho, emprego e renda à população LGBT; ii) promoção de apoio à realização de cursos de capacitação visando à inserção de LGBTs no mercado de trabalho formal e regulamentação da prostituição; iii) efetivação e ampliação de políticas de combate ao preconceito, assédio moral e discriminação de LGBTs no ambiente de trabalho.

Percorrido este caminho sobre a construção das políticas e do conteúdo dos documentos, cabe, agora, conhecer as ações realizadas para a efetivação do direito ao trabalho e emprego sem discriminação por identidade de gênero e orientação sexual no contexto brasileiro.

Não há nenhuma legislação brasileira que regulamenta sobre Trabalho, Emprego e Renda que se refira à comunidade LGBT, tanto em relação à orientação sexual quanto à identidade de gênero. No mapeamento de políticas públicas e direitos LGBTs no Brasil, encontramos documentos do Poder Executivo que balizaram as políticas públicas durante as gestões do Partido dos Trabalhadores no governo federal, e é neles que nos ateremos nos desdobramentos das ações propostas e formuladas nestes documentos.

Mello, Brito e Maroja (2012) asseveram que:

As ações e os programas mapeados em nossa pesquisa são, em princípio, produto do reconhecimento, pelo Poder Executivo dos diferentes níveis de governo (federal, estadual e municipal), da necessidade de políticas públicas de combate ao preconceito, à discriminação e à exclusão que atingem essa população. E mais: tais ações e programas são particularmente importantes num cenário em que o Poder Legislativo ainda não aprovou nenhuma lei que assegure direitos civis e sociais à população LGBT (p. 409).

Em relação ao trabalho, o programa BSH refere-se apenas às questões de não discriminação no ambiente de trabalho, que, por sua vez, é a ação VII do referido plano, e, de acordo com o relatório supracitado, "o programa não traz definições precisas sobre como serão efetivadas as iniciativas de combate à discriminação no trabalho" (IRINEU et al., 2010, p. 177).

Além disso, as referências ao trabalho no $\mathrm{BSH}$ "se restringem à realidade de BTLG que atuam profissionalmente no campo da formalidade. O programa não problematiza questões, por exemplo, como a profissionalização da prostituição" (IRINEU et al., 2010, p. 179). Apontamos também para o papel secundário dado às políticas e ações referentes ao trabalho quando comparado às propostas de saúde e educação, que, basicamente, representam a maior parte de concentração das ações, como mencionamos anteriormente no texto.

Sobre o estabelecimento e a previsão orçamentária do BSH, elementos que incidem diretamente na efetividade das ações governamentais, é possível verificar que:

Mesmo que a criação deste programa tenha tido um grande significado, a forma como o governo federal conduziu o processo de implementação foi problemática, como baixa previsão orçamentária, pequena quantidade de técnicos vinculados ao programa e ações que se alocaram muito mais sob a responsabilidade do movimento social do que Poder Executivo (IRINEU et al., 2010, p. 176). 
Diferentemente das ações previstas no BSH, as proposições contidas nos Anais da I Conferência Nacional de Políticas Públicas LGBT avançam ao indicar a necessidade de formação profissional de LGBTs, regulamentação do trabalhador/a do sexo, além de trazer novamente as demandas já levantadas no BSH. Percebido isso, compreendemos que a elaboração de diretrizes de políticas públicas para LGBTs no campo do trabalho, emprego e renda, com a participação da sociedade civil, avançaram, buscando levantar questões que o BSH não havia mencionado e que foram observadas no I Plano Nacional LGBT.

Já as diretrizes propostas nos Anais da II Conferência Nacional LGBT, que compilaram as deliberações da II Conferência Nacional LGBT, não se tornaram um segundo Plano Nacional de Políticas Públicas, como ocorreu com as propostas da I Conferência, gerando o I Plano de Políticas Públicas para a população LGBT. Nesse sentido, as diretrizes da II Conferência serviram ao Poder Executivo mais como balanço das ações anteriores e busca de continuidade das ações não desenvolvidas ou parcialmente desenvolvidas, não havendo avaliação posterior da efetivação destas ações nos documentos oficiais.

A primeira diretriz presente nos Anais menciona emprego e renda, não priorizando apenas o trabalho. Além disso, dá como possível solução para a inserção de LGBTs no mercado de trabalho a criação de campanhas e incentivos a empresas e organizações que adotarem políticas afirmativas. A segunda e terceira diretrizes somente referem-se às políticas de trabalho e também não abordam a forma de execução da proposta, apesar de mencionarem questões pertinentes, como a regulamentação da prostituição e o mercado de trabalho informal.

Posteriormente, com a não publicação do segundo Plano mesmo com grande pressão do movimento social, a SDH/PR e o CNCD-LGBT passaram a investir seu fôlego no que ficou conhecido como "Sistema Nacional de Enfrentamento à Violência LGBT". O Sistema começou a ser desenhado ainda em 2013, mas seu processo de instalação foi iniciado por meio de abertura de um edital da SDH/PR, convocando a sociedade civil e governos estaduais a parcerias, porém a conjuntura eleitoral de 2014 iniciou o processo de estagnação de grande parte das ações governamentais da pasta, que, com o impeachment de Dilma Rousseff, tomou outros rumos ainda pouco possíveis de uma avaliação detalhada, mas certamente com um prejuízo político histórico à democracia brasileira. Diante disso, pode-se perceber a instabilidade e a descontinuidade do debate de diversidade sexual e de gênero no campo das políticas públicas brasileiras.

Apesar do recorte temporal que escolhemos entre 2004 e 2014, é necessário mencionar, no presente trabalho, o Decreto № 8.727, de 28 de abril de 2016, assinado pela presidenta à época, Dilma Rousseff, que "dispõe sobre o uso do nome social e o reconhecimento da identidade de gênero de pessoas travestis e transexuais no âmbito da administração pública federal direta, autárquica e fundacional" (BRASIL, 2016).

Com esse decreto vigorando, há efeitos mediatos no âmbito do trabalho que coadunam com as propostas aprovadas nas últimas Conferências. Primeiramente, o decreto vai ao encontro da proposta de respeito à identidade de gênero no ambiente de trabalho, ou seja, pessoas travestis e transexuais que exercitarem atividade laboral no âmbito federal poderão utilizar o nome que se reconhece. Segundo, fica proibido qualquer tipo de discriminação no âmbito federal no tratamento com travestis e transexuais, conforme parágrafo único do artigo 2 ㅇ. 


\section{Humanos e}

Democracia

Vale mencionar, também, que, em razão da inércia do Poder Legislativo, somada aos inúmeros processos de pessoas LGBTs buscando direitos à conjugalidade e parentalidade no âmbito judiciário, em 2011 o Supremo Tribunal Federal proferiu o Acórdão da Ação Direta de Inconstitucionalidade 4.277-Df - Supremo Tribunal Federal -, que por sua vez, basicamente, reconhece a inconstitucionalidade de distinção de tratamento legal às uniões estáveis constituídas por pessoas de mesmo sexo. Posteriormente, a fim de regular e garantir o julgado do STF, o Conselho Nacional de Justiça editou a Resolução no 175, de 14 de maio de 2013.

\section{IDENTIFICANDO AS POLÍTICAS PÚBLICAS DE TRABALHO, EMPREGO E RENDA NA ARGENTINA}

A Argentina possui similaridades com o Brasil em alguns processos de sua história. Os movimentos sociais LGBTs surgem na década de 70 do século 20 e o país também viveu um longo período ditatorial. Os anos de 1980 e 1990 serão importantes para a construção democrática de ambos os países, que tiveram a experiência de governos de centro-direita, como Carlos Menem e Fernando Collor, e, posteriormente, iniciou um período de mais de uma gestão, tendo a esquerda à frente do governo federal, como os Kischner, Lula e Dilma. A experiência dos governos populares alinhou-se, em ambos países, com o neodesenvolvimentismo e com a consolidação de políticas neoliberais. A constituição do Legislativo nos países, todavia, tem marcadamente distinções que demonstram na Argentina uma grande expressão do poder do catolicismo, e no Brasil a forte emergência do neopetencostalismo na política partidária e nas esferas de poder, especialmente no Legislativo.

Quanto às políticas de trabalho, emprego e renda na Argentina, analisou-se primeiramente o conteúdo do documento "Da lei à prática: conceitos de um paradigma igualitário"1, publicado em 2012 pelo Ministério de Desenvolvimento Social. ${ }^{2}$ Este documento "tem como objetivo repensar algumas de nossas práticas, olhares e ações diárias, enraizados em uma sociedade que mantém estereótipos e lugares predeterminados para mulheres e homens ${ }^{3 \prime}$ (ARGENTINA, 2012, p. 9).

O documento citado discorre sobre a trajetória dos direitos LGBTs na Argentina após a ascensão do Partido Justicialista à presidência da república no ano de 2003. "Da lei à prática: conceitos de um paradigma igualitário" nos mostra que as Políticas Públicas para a População LGBT da Argentina, em suma, são garantidas por força de lei. Além disso, manifesta que:

O Ministério de Desenvolvimento Social da Nação soma esforços para a construção de uma cidadania diversa e equitativa a partir da criação de uma Coordenação Nacional de Diversidade Sexual, com o objetivo de facilitar todas as linhas de ação para melhorar a qualidade de vida e promover os direitos das populações de LGBTTTI $^{4}$ (ARGENTINA, 2012, p. 24).

\footnotetext{
De La Ley a La Práctica: Conceptos Desde un Paradigma Igualitario (2012).

Ministerio de Desarrollo Social.

3 Tiene como objetivo repensar algunas de nuestras prácticas, miradas y acciones cotidianas, arraigadas en una sociedad que sostiene estereotipos y lugares predeterminados para las mujeres y los hombres (ARGENTINA, 2012, p. 9).

4 El Ministerio de Desarrollo Social de la Nación suma esfuerzos para la construcción de una ciudadanía diversa y equitativa a partir de la creación de una Coordinación Nacional de Diversidad Sexual, con el objetivo de facilitar todas las líneas de acción para mejorar la calidad de vida y promover los derechos de las poblaciones de LGBTTTI (ARGENTINA, 2012, p. 24).
} 
A lei do matrimônio igualitário (Lei 26.618) da Argentina foi promulgada pela presidenta Cristina F. Kirchner em 21 de julho de 2010, que, por sua vez, diz que "o matrimônio terá os mesmos requisitos e efeitos, com independência de que os contraentes sejam do mesmo sexo ou de diferente sexo"5 (ARGENTINA, 2015, p. 33).

Em julho de 2012, a presidenta assinou o "Decreto de Necessidade e Urgência (DNU n 1.006)", ${ }^{6}$ que "baseou-se em "estritas razões de igualdade" equiparando os direitos das crianças nascidas antes da Lei do Matrimônio Igualitário com as que nasceram mais tarde, o que permitiu a emissão de novos certificados de nascimento contemplando os dados de ambas mães e sobrenome duplo7"' (ARGENTINA, 2015, p. 34).

Em maio de 2012, a presidenta C. F. Kirchner promulgou a "Lei no 26.743 de Identidade de Gênero"8 (ARGENTINA, 2012), que tem como aspectos principais:

a) travestis, transexuais, transgêneros e homens/machos transexuais têm o direito de reconhecer sua identidade de gênero auto percebida e receber um tratamento digno; $b$ ) reconhece o direito humano fundamental de todas as pessoas ao reconhecimento de sua identidade de gênero, seja tratado de acordo com ela, ao livre desenvolvimento de sua pessoa e, em particular, seja identificado dessa forma no Certificado de Nascimento e no Documento Nacional de Identidade (DNI); c) em nenhum caso pode ser exigido como condição uma intervenção cirúrgica, nem terapias hormonais ou outros tratamentos psicológico e médico e d) perspectiva despatologizante, desjudicializante e desestigmatizante (ARGENTINA, 2015, p. 35). ${ }^{9}$

Em relação às políticas públicas de trabalho e emprego, encontramos um documento intitulado "Livreto de inclusão de trabalho para o coletivo TRANS"10, produzido no ano de 2013 pelo Ministério de Trabalho, Emprego y Seguridade Social da Nação ${ }^{11}$, e também a

Linha de Inclusão do Trabalho para Travestis, Transexuais e Transgêneros (Trans), a fim de contribuir para melhorar a empregabilidade desta população através da implementação de diferentes ferramentas (ARGENTINA, 2013, p. 9).

\footnotetext{
El matrimonio tendrá los mismos requisitos y efectos, con independencia de que los contrayentes sean del mismo o de diferente sexo (ARGENTINA, 2015, p. 34).

6 Decreto de Necesidad y Urgencia (DNU N 1.006).

7 Se basó en "estrictas razones de igualdad" equiparando los derechos de los niños y niñas nacidos/as antes de la Ley de Matrimonio Igualitario con los nacidos/as después, lo que permitió emitir nuevas actas de nacimiento completando los datos de ambas madres y el doble apellido (ARGENTINA, 2015, p. 34).

8 Ley No 26.743 de Identidad de Género

9 a) travestis, transexuales, transgéneros y hombres/varones trans tienen derecho a que se reconozca su identidad de género autopercibida y a recibir un trato digno; b) reconoce el derecho humano fundamental de toda persona al reconocimiento de su identidad de género, a ser tratada de acuerdo a ella, al libre desarrollo de su persona y en particular, a ser identificada de ese modo en la Partida de Nacimiento y el Documento Nacional de identidad (DNI); c) en ningún caso se pueden exigir como condición una intervención quirúrgica, ni terapias hormonales u otro tratamiento psicológico o médico e d) perspectiva despatologizante, desjudicializante y desestigmatizante.

${ }^{10}$ Cuadernillo de Inclusión Laboral para el colectivo TRANS (2013).

${ }^{11}$ Ministerio de Trabajo, Empleo y Seguridad Social de la Nación.
} 


\section{Humanos e \\ Democracia}

De acordo com o documento, "é prioridade do Ministério promover a inserção laboral de trabalhadores e trabalhadoras com problemas de emprego, particularmente aqueles que pertencem a grupos vulneráveis"12 (ARGENTINA, 2013, p. 9). Assim sendo, há dois programas de emprego governamentais: o "Programa Jovens com Mais e Melhor Trabalho" (ARGENTINA, 2013, p. 10) e o "Programa Seguro de Capacitação e Emprego (SCyE)" (ARGENTINA, 2013, p. 10). ${ }^{13}$ Acessando alguns desses programas, os/as beneficiados/as terão acesso a nove tipos de ferramentas, sendo elas:

A) Suporte econômico mensal; B) Tutoriais de trabalho social para pensar e desenvolver seu próprio treino profissional e profissional; C) Atividades de Orientação Laboral e Pesquisa de Trabalho; D) Conclusão dos estudos primários e secundários; E) Cursos de formação profissional gratuita; F) Programa de Emprego Independente; G) Programa de treinamento de trabalho e programa de inserção; H) Trabalho no setor público e privado; I) Acesso à Rede Federal de Serviços de Emprego ${ }^{14}$ (ARGENTINA, 2013, p. 11).

A partir desse momento avaliaremos as ações da Argentina. De acordo com "Da lei à prática: conceitos de um paradigma igualitário" (2012), a Argentina aprovou, em 2012, a Lei no 26.746, conhecida como Lei de Identidade de Gênero, que reconhece a travestis, transexuais e transgêneros o direito de se reconhecer quanto à identidade de gênero que se percebem. Esse documento, assim como o Decreto brasileiro que reconhece identidade de gênero no âmbito federal, é de fundamental importância para o trabalho e emprego de pessoas Trans. A lei argentina de identidade de gênero,

Apesar de ser uma lei que muitos especialistas concordam como uma das mais avançadas do mundo, não recebeu atenção notável na mídia. Mantém o binômio sexual, mas contempla mudanças de registro sem autorização judicial ou médica, e o direito à saúde de travestis, transexuais e transgêneros através de intervenções cirúrgicas e/ou tratamentos hormonais para aqueles que o necessitam (TABBUSH et al., 2016, p. 7). ${ }^{15}$

Sem dúvidas as legislações argentinas apresentam avanço formal nos direitos da população LGBT. Para tanto, é necessário constituir ações e programas do campo das políticas públicas para atuar juntamente com a legislação. Entendemos a LGBTfobia como um fenômeno cultural que observa a não correspondência à heterossexualidade, bem como os marcadores de gênero, alimentado pelo ódio e fundamentalismo religioso. Nesse sentido, a criação de leis e/ou programas encontra resistência e muita dificuldade na efetivação para aquilo que se propõem.

\footnotetext{
${ }^{12}$ Es prioridad del Ministerio promover la inserción laboral de los trabajadores y trabajadoras con problemas de empleo, en particular de aquellos y aquellas que pertenecen a colectivos vulnerados (ARGENTINA, 2013, p. 9).

${ }^{13}$ Programa Jóvenes con Más y Mejor Trabajo (PJcMyMT)" (ARGENTINA, 2013, p. 10) y "Programa Seguro de Capacitación y Empleo (SCYE)" (ARGENTINA, 2013, p. 10).

${ }^{14}$ a) Apoyo Económico Mensual; b) Tutorías socio-laborales para pensar y desarrollar tu propio trayecto formativo y ocupacional; c) Actividades de Orientación Laboral y Apoyo a la Búsqueda de Empleo; d) Finalización de Estudios Primarios y Secundarios; e) Cursos de Formación Profesional gratuitos; f) Programa de Empleo Independiente; g) Programa de Entrenamiento para el Trabajo y Programa de Inserción; h) Laboral en el sector público y privado; e i) Acceso a la Red Federal de Servicios de Empleo" (ARGENTINA, 2013, p. 11).

${ }^{15}$ A pesar de tratarse de una ley que muchos/as expertos/as coinciden es una de las más avanzadas en el mundo, no recibió atención mediática notoria. La misma mantiene el binomio sexual, pero contempla cambios registrales sin autorización judicial o médica, y el derecho a la salud de travestis, transexuales y transgenero a través de intervenciones quirúrgicas y/o tratamientos hormonales para quienes lo requiriesen (TABBUSH et al., 2016, p. 7).
} 
O "Livreto de inclusão de trabalho para o coletivo TRANS" (2013), que, por sua vez, instituiu a "linha de inclusão laboral para pessoas TRANS"16 (ARGENTINA, 2013, p. 9), tem o objetivo de contribuir para a melhora da empregabilidade desta população em questão. Nesse sentido, as pessoas transexuais seriam incluídas nos dois programas de emprego governamentais de acesso à toda população, quando encontraram nove tipos de prestação de benefícios. $A$ eficácia desta política é reduzida no atendimento à população transexual. Por ser um programa de cunho universalista, que oferece algumas ações para inserção no mercado de trabalho, não observa as especificidades de cada população em situação de vulnerabilidade e não se atenta aos motivos concretos que marginalizam a população transexual, como a evasão escolar e as barreiras no acesso à saúde, situações que corroboram a falta de acesso ao mercado de trabalho formal.

\section{CONSIDERAÇÕES FINAIS}

Como salientamos anteriormente, Argentina e Brasil possuem uma formação social, econômica, política e cultural distintas em seus processos coloniais, todavia também possuem aspectos semelhantes. Os dois países passaram por ditaduras militares, e têm suas constituições de Estado Democrático de Direito garantidas, de certa forma, há pouco tempo, e viram nos anos 2000 a ascensão de governos populares à presidência da república. Além disso, os dois países têm uma forte presença das religiões de matriz judaico-cristã e também sofrem com os altos índices de feminicídio, reflexo da produção de um sexismo ancorado em uma masculinidade bélica.

Nessa perspectiva, é necessário destacar que,

nos países de frágil tradição democrática, mas não só nesses, um dos principais desafios para as gestoras/es é a formulação de políticas públicas capazes de assegurar desenvolvimento econômico e promover a inclusão social de grandes parcelas marginalizadas da população (SOUZA, 2003b). Nesse contexto, as políticas públicas deveriam ser globais, em três sentidos: a) por dizerem respeito ao Estado, e não apenas ao governo; b) por não deverem se restringir ao período de um único governo; e c) por necessariamente contarem, em sua elaboração, com a participação do conjunto da sociedade civil, incluindo ONGs, empresas, igrejas, academia, mídia, etc. (OBSERVATÓRIO, 2004), constituindo aquilo que Frey (2000) chama de policy network. Nessa perspectiva, "o objetivo de toda política pública é a consagração do Estado de direito, a democracia e a extensão do gozo dos direitos humanos civis, culturais, econômicos, políticos e sociais" (OBSERVATÓRIO, 2004, p. 10, tradução nossa) (MELLO; AVELAR; MAROJA, 2012, p. 291).

No Brasil, até o presente momento, não há nenhuma legislação aprovada referente aos direitos da população LGBT - apesar de o Poder Judiciário ter reconhecido o casamento entre pessoas do mesmo sexo -, enquanto na Argentina existem três leis específicas destinada a este segmento. No Brasil, desde 2004 o governo federal vem desenvolvendo ações no campo das políticas públicas, que, pela sua fragilidade e descontinuidade, têm dificuldade de uma ampla efetivação, sobretudo pela falta de orçamentou e incipiência da instituição destas nos

\footnotetext{
${ }_{16}$ Línea de inclusión laboral para personas TRANS (ARGENTINA, 2013, p. 9).
} 


\section{Humanos e}

Democracia

âmbitos estadual e municipais. Na Argentina, apesar da "Lei no 23.592 de Atos Discriminatórios $^{117}$ de 1997, que se aplica à discriminação por orientação sexual e identidade de gênero, a primeira ação específica do Poder Executivo foi a promulgação da Lei do Matrimônio Igualitário (Lei 26.618) em 2010.

Percebe-se assim, que enquanto a maioria dos países da U.E. [União Europeia] e alguns na América Latina, como Argentina e Uruguai, tem apostado na regulamentação jurídico-legal dos direitos LGBT, o Brasil tem apostado nas ações do poder executivo e retrocedido na pauta dos direitos humanos no legislativo. $O$ judiciário permanece regulando matérias individuais, que apesar de se tornarem jurisprudências tem onerado a cidadania das pessoas LGBT e as condicionando a processos de judicialização dos direitos humanos (MERIQUI; IRINEU, 2013, p. 6).

Desse modo, no Brasil, a relação entre o Estado e a população vem se construindo a partir de órgãos de controle social, seja com representação da sociedade civil nos Conselhos ou a partir da participação nas Conferências. Apesar de ser um espaço de participação social necessário, são insuficientes para assegurarem os direitos e políticas da população LGBT, quando o Legislativo não se esforça para tornar as ações de governo políticas de Estado.

Em relação ao Brasil, também é importante mencionar que as políticas públicas para a população LGBT são frágeis, pois, além de não possuírem orçamento próprio, não têm uma regulamentação jurídico-legal, sendo, muitas vezes, criadas a partir de simples portarias. Além disso, como visto, dentro do rol das políticas LGBT, há determinadas políticas, como as de saúde e educação, que desenvolvem ações há um maior tempo, dado o histórico de luta contra o HIV/aids e o debate da inclusão na educação, enquanto outras áreas, como o trabaIho, emprego e renda, por sua perspectiva universalista, ainda não conseguem qualquer avanço na transversalidade de gênero e orientação sexual. Ou seja, "a prioridade construída pelo movimento LGBT e a definição do que 'é mais importante demandar agora' também sinaliza o motivo da insuficiência das ações e programas nestas três áreas" (IRINEU et al., 2010, p. 180).

No contexto brasileiro, em relação às políticas públicas LGBT de Trabalho, Emprego e Renda, ao analisar os documentos oficiais do corpus da pesquisa, percebemos que as propostas da sociedade civil e do poder público para essas áreas acabam se limitando a ações que visam: a) a combater a LGBTfobia nos ambientes de trabalho; b) à qualificação profissional dos grupos discriminados; e c) à criação de benefícios ou prêmios para empresas que contratam pessoas LGBTs.

As políticas de Trabalho, Emprego e Renda da Argentina para a população LGBT são encontradas na "Ley № 26.743 de Identidad de Género" (ARGENTINA, 2012), que reconhece a existência das pessoas transexuais, gerando, assim, efeitos no âmbito do trabalho. Percebe-se que trabalho e emprego para as pessoas trans fazem parte de um universo de políticas para todas as pessoas que estão desempregadas e que cumprem os requisitos dos programas, mostrando, novamente, os dilemas entre universalidade e especificidade das políticas públicas em um contexto neoliberal de seletividade populacional (PEREIRA, 2006).

\footnotetext{
${ }^{17}$ Ley no 23.592 de Actos Discriminatorios" (1997).
} 
Então, embora na Argentina as políticas públicas para a população LGBT têm se garantido por meio de leis do ponto de vista formal, isso não tem implicado em efetivação cotidiana dessas decisões. Observa-se a necessidade de instalação de políticas públicas previstas na regulamentação legal acerca do acesso desta população à cidadania. Avaliando os marcos legais argentinos, percebemos uma gama de direitos civis garantidos por força de lei, abandonando os direitos sociais, como o trabalho e emprego.

De modo geral, em ambos os países verifica-se que lésbicas, gays e bissexuais têm mostrado uma recepção maior às pautas do campo dos direitos civis, sem uma atenção às demandas em decorrência da violência ou vulnerabilidade socioeconômica. Em relação ao segmento T, apesar da inclusão nos programas governamentais, o enfoque no nome civil sobressai em relação às demandas por direitos sociais. Os movimentos LGBTs na Argentina e no Brasil têm historicamente destacado como prioridade de pautas o reconhecimento do matrimônio, a adoção e, posteriormente, a criminalização da homofobia.

Cabe ressaltar que, ao longo dessa história dos movimentos LGBTs, alguns grupos se consolidaram como fortes negociadores no diálogo com os governos, e outros têm optado por estratégias menos aliadas ao advocacy e incidido mediante denúncias internacionais ou de ações micropolíticas no campo da cultura. Ou seja, os movimentos sociais LGBTs não são uníssonos e se vinculam a projetos societários de maneira distinta. Globalmente, portanto, as pautas relacionadas ao direito à família têm sido construídas prioritariamente por estes grupos que possuem um diálogo estabelecido com o governo. Já as demandas relacionadas à criminalização da homofobia tergiversaram, no Brasil, a outros grupos políticos contra hegemônicos no diálogo com o poder público. Com intensas negociações de consenso deste movimento hegemônico com grupos políticos religiosos, todavia, esvaziou-se a proposta inicial, atrelando-a a uma proposta que certamente serviria apenas para a ampliação do Estado Penal brasileiro.

Conclui-se, assim, que em um contexto de avanço neoliberal, recrudescimento do conservadorismo e de radicalização do conflito capital-trabalho, as pautas relacionadas aos direitos sociais, que envolvem redistribuição socioeconômica, acabam por não ter espaço, enquanto o reconhecimento da diferença, especialmente relacionados ao direito a família e patrimônio tendem a ganhar uma maior adesão em governo democrático. Assim, fica o desafio de intensificação das lutas sociais por defesa e garantia de ampliação dos direitos sociais à população LGBT, mas também à classe trabalhadora de modo geral, haja vista o contexto de reformas e desmantelamento dos direitos conquistados que vivemos atualmente.

\section{REFERÊNCIAS}

ALMEIDA, G. da S; PILAR, A; GEBRATH, Z. As relações de trabalho como um aspecto da assistência à saúde de pessoas trans. In: COELHO, M. T. Á. D; SAMPAIO, L. L. P. Transexualidades: um olha multidisciplinar. Salvador: Edufba, 2014.

ARGENTINA. Argentina inclusiva: Guía de términos y conceptos sobre diversidad sexual desde la perspectiva de derechos. 2015. Disponível em: http://www.trabajo.gob.ar/downloads/otros/151111_guia_diversidad_doc.pdf. Acesso em: 8 mar. 2016.

ARGENTINA. Cuadernillo de Inclusión Laboral para el colectivo TRANS. 2013. Disponível em: http://www.trabajo. gob.ar/downloads/difusion/131202_cuadernillo_trans.pdf. Acesso em: 8 mar. 2016. 


\section{Humanos e}

Democracia

ARGENTINA. Ministerio de Desarrollo Social. De La Ley a La Prática: Conceptos Desde Un Paradigma Igualitario. 2012. Disponível em: http://www.desarrollosocial.gob.ar/Uploads/i1/47\%20De\%20la\%20Ley\%20a\%20la\%20 practica\%20-\%20Diversidad\%20sexual.pdf. Acesso em: 17 abr. 2015.

BAUER, Martin W.; GASKELL, George (ed.). Pesquisa qualitativa com texto, imagem e som: um manual prático I. Petrópolis, RJ: Editora Vozes, 2002.

BRASIL. Conselho Nacional de Combate à Discriminação. Brasil sem homofobia: Programa de combate à violência e à discriminação contra GLTB e promoção da cidadania homossexual. Brasília: Ministério da Saúde, 2004.

BRASIL. Secretaria de Direitos Humanos da Presidência da República. Conferência Nacional de Lésbicas, Gays, Bissexuais, Travestis e Transexuais - LGBT, 2., 2011. Anais [...]. Brasília, 2011.

BRASIL. Decreto no 8.727, de 28 de abril de 2016. Brasília, DF, Disponível em: http://www.planalto.gov.br/ccivil_03/_Ato2015-2018/2016/Decreto/D8727.htm. Acesso em: 7 jul. 2016.

BUTLER, Judith. Problemas de gênero. Feminismo e subversão da identidade. Rio de Janeiro: Civilização Brasileira, 2003.

FOUCAULT, Michel. Vigiar e punir. 1999. Disponível em: http://comunicacaodasartesdocorpo.files.wordpress. com/2013/11/foucault-michel-vigiar-e-punir.pdf. Acesso em: 17 out. 2014.

IRINEU, Bruna Andrade et al. Políticas públicas de trabalho, assistência social e previdência social para a população LGBT: "caminhos paralelos" ou "estradas que se cruzam"? 2010. Disponível em: https://www.sertao.ufg.br/ politicaslgbt/interna.php?id=6. Acesso em: 8 mar. 2016.

LE BRETON, David. A sociologia do corpo. 2. ed. Tradução Sonia M. S. Fuhrmann. Petrópolis, RJ: Vozes, 2007.

LOURO, Guacira Lopes. Um corpo estranho: ensaios sobre sexualidade e teoria queer. Belo Horizonte, MG: Autêntica, 2004.

MACHADO, Maria das Dores Campos; PICCOLLO, Fernanda Delvalhas (org.). Religiões e homossexualidades. Rio de Janeiro: Editora FGV, 2010.

MELLO, Luiz; AVELAR, Rezende Bruno de; MAROJA, Daniela. Por onde andam as políticas públicas para a população LGBT no Brasil. 2012. Disponível em: http://www.scielo.br/pdf/se/v27n2/a05v27n2.pdf. Acesso em: 30 ago. 2017.

MELLO, Luiz; BRITO, Walderes; MAROJA, Daniela. Políticas públicas para uma população LGBT no Brasil: notas sobre alcances e possibilidades. Cafajeste. Pagu [online]. 2012, n.39 [cited 2020-12-01], p. 403-429. Disponível em: http://www.scielo.br/scielo.php?script=sci_arttext\&pid=\$0104-83332012000200014\&lng=en\&nrm=iso. ISSN 0104-8333. https://doi.org/10.1590/S0104-83332012000200014.

MERIQUI, Mariana; IRINEU, Bruna Andrade. As políticas públicas para população LGBT no Brasil e seus impactos na conjuntura internacional: "para inglês ver"? 2013. Disponível em: http://www.fg2013.wwc2017.eventos. dype.com.br/resources/anais/20/1373550563_ARQUIVO_trabalhofazendogenero.pdf. Acesso em: 15 mar. 2017. NATIVIDADE, Marcelo; OLIVEIRA, Leandro de. As novas guerras sexuais: diferença, poder religioso e identidades LGBT no Brasil. 1. ed. Rio de Janeiro: Garamond, 2013.

PEREIRA, Potyara. Necessidades humanas: subsídios à crítica dos mínimos sociais. São Paulo: Cortez, 2006.

PRATES, Jane C.; PRATES, Flávio C. Problematizando o uso da técnica de Análise Documental no Serviço Social e no Direito. Sociedade em Debate, Pelotas, 15(2), p. 111-125, jul./dez. 2009.

SOUZA, Celi. "Políticas públicas: questões temáticas e de pesquisa". Caderno CRH, Salvador, n. 39, v. 16, p. 11-24, 2003.

TABBUSH, Constanza et al. Matrimonio igualitario, identidad de género y disputas por el derecho al aborto en argentina. La política sexual durante el kirchnerismo (2003-2015). 2016. Disponível em: http://www.e-publicacoes. uerj.br/index.php/SexualidadSaludySociedad. Acesso em: 14 jul. 2016. 